\title{
Prevalence of hypertension and prehypertension in Nepal: a systematic review and meta-analysis
}

\author{
Yun Huang ${ }^{1}$, Pi Guo², Biraj M. Karmacharya ${ }^{3}$, Sharvesh Raj Seeruttun ${ }^{4}$, Dong Roman X $\mathbf{u}^{3}$ and Yuantao Hao ${ }^{1,3^{*}}$
}

\begin{abstract}
Background: Studies regarding blood pressure of Nepal have demonstrated a contrasting prevalence. We aimed at providing a generalized estimate of the prevalence of hypertension and prehypertension in urban, suburban, and rural areas of Nepal.

Methods: This systematic review followed PRISMA guidelines. A thorough search of PubMed, EMBASE, and Web of Science was performed, and studies satisfying the eligibility criteria were reviewed. Pooled prevalence was calculated by random-effects model, and the sources of heterogeneity were explored with meta-regression and subgroup analysis.

Results: Twenty-three studies with 99,792 subjects were identified, and the estimated rate of hypertension and prehypertension were found to be $27.3 \%$ (95\% Cl: 23.8-30.9) and 35.4\% (30.3-40.8). The prevalence of hypertension was 28.4\% (22.4-34.7), 25.5\% (21.4-29.8), and 24.4\% (17.9-31.6) among urban, suburban, and rural populations, respectively. Moreover, rates of hypertension were found to be substantially higher in male $(31.6 \%, 27.3-36.1)$ compared to female (20.0\%, 14.2-26.6), and significantly higher among the middle-aged ( $\geq 40$ years; $36.8 \%, 29.4-44.5)$ than among younger adults (< 40 years; $13.2 \%, 9.2-17.7)$. Further, prehypertension prevalence was found to be highest in rural areas (40.4\%, 25.4-56.4) followed by urban areas (29.3\%, 20.8-38.5) and lowest in suburban areas (25.5\%, 18.9-32.7).
\end{abstract}

Conclusions: Our study identified an alarming situation of hypertension among Nepalese males and middle-aged, and a situation of concern with prehypertension in rural areas affecting almost $40 \%$ of the population.

Keywords: Hypertension, Prehypertension, Prevalence, Nepal, Systematic review, Meta-analysis

\section{Background}

High blood pressure (HBP) is responsible for more than half of all strokes and coronary disease [1], and is now considered the biggest contributor to the global burden of non-communicable diseases (NCDs) and mortality [2]. The World Health Organization (WHO) reported HBP to be more alarming in low- and middle-income countries (LMICs) [3]; with Nepal being no exception as it is currently suffering from a double burden of diseases due to its

\footnotetext{
* Correspondence: haoyt@mail.sysu.edu.cn

'Department of Medical Statistics and Epidemiology, School of Public Health, Sun Yat-sen University, No. 74 Zhongshan Road II, Guangzhou 510080, Guangdong Province, People's Republic of China

${ }^{3}$ Sun Yat-sen Global Health Institute (SGHI), School of Public Health and Institute of National Governance of Sun Yat-sen University, Guangzhou 510275, Guangdong Province, China

Full list of author information is available at the end of the article
}

transition from a phase of communicable diseases to that of a higher prevalence of NCDs [4].

One study analyzing HBP in developing countries pointed out that the prevalence of hypertension in Nepal was still at a low level $(<20 \%)$ [5], in contrast to another study conducted in the Birendranagar municipality of the Surkhet District which indicated a more severe status with an HBP percentage rising as high as $38.9 \%$ [6]. This discrepancy may have emerged due to the diverse prevalence of hypertension in different populations of Nepal. Further, the rate of prehypertension, which was also reported notably different from each other (range: 22.1-48.0\%) [7, 8], will undeniably evolve to HBP if not controlled. A more generalized estimate of hypertension and prehypertension prevalence will therefore provide an important background to health-related authorities to understand the disease's status in Nepal. Although there were three

(c) The Author(s). 2019 Open Access This article is distributed under the terms of the Creative Commons Attribution 4.0 International License (http://creativecommons.org/licenses/by/4.0/), which permits unrestricted use, distribution, and 
nationwide studies aiming at probing the HBP situation in Nepal [9-11], they reported diverging hypertension and prehypertension status which probably arose due to the different age compositions of respondents and other confounders. The actual blood pressure (BP) status in Nepal urges further verification. At present, there has been no systematic review of the Nepalese prehypertension situation. Limited existing meta-analyses for hypertension have been broadly focused either on LMICs, Asian populations, or the South Asian Association for Regional Cooperation (SAARC), but none has been focused specifically on Nepal. In addition, previous studies concentrated on comparing BP status between urban and rural areas [9, 10], while many epidemiological studies were conducted in suburban areas and the prevalence of HBP in this region need to be clarified, and targeted policies may benefit from regional analysis.

Thence, we aimed at filling this gap using strong meta-analytic evidence by merging existing scientific literature to obtain a robust generalized estimate of the prevalence of both hypertension and prehypertension in the urban, suburban, and rural parts of Nepal.

\section{Methods}

\section{Study design}

This systematic review was conducted following PRISMA (Preferred Reporting Items for Systematic Reviews and Meta-Analyses) guidelines [12], and the PRISMA checklist is provided as an Additional file 1. Although the criteria for HBP is evolving, in our study the presence of prehypertension was still defined as systolic BP $120-139 \mathrm{mmHg}$ and diastolic BP $80-89 \mathrm{mmHg}$; and hypertension was defined as an average $\mathrm{BP} \geq 140 / 90 \mathrm{mmHg}$ and/or the use of antihypertensive medication according to the JNC VII report [13], because the latest criteria is not widely accepted yet and all the compiled studies complied with the JNC VII report. The method used in this study was composed of the following steps: (1) a survey of the literature for relevant studies on the prevalence of hypertension in Nepal; (2) data extraction; and after pooling data, (3) meta-analysis.

\section{Search strategy and selection criteria}

An initial search for studies by a combination of Medical Subject Headings (MeSH) terms consisting of 'hypertension' and its relevant synonyms was performed using PubMed, EMBASE, and Web of Science. The search was restricted to publications from January 2000 to August 2018 that were conducted on the human species and published in the English language. (We also searched relevant databases for possible publications in Nepalese and Chinese but none was found). The results were further narrowed by adding 'Nepal' as another key word. The search details of PubMed were as follows: (("hypertension" [MeSH Terms] OR "hypertension"[All Fields]) OR "high blood
pressure"[All Fields] OR "elevated blood pressure"[All Fields] OR "raised blood pressure"[All Fields]) AND ("nepal"[MeSH Terms] OR "nepal"[All Fields]) AND ((“2000/01/01”[PDAT]: “2018/08/31”[PDAT]) AND "humans"[MeSH Terms] AND English[lang]). A manual search for additional potential studies was performed using the references cited in the retrieved reviews and original research articles. The reason why excluding studies conducted before year 2000 was the definition of 'hypertension' we use being lastly revised and implemented in year 1999.

Two authors (Yun Huang, Pi Guo) independently reviewed the titles and abstracts culled from the searches, and full texts of potentially eligible studies were downloaded and further screened for final inclusion in our study. The eligibility criteria for inclusion were: (1) original articles from non-hospitalized and population-based surveys reporting HBP prevalence (or containing data to calculate the prevalence); (2) respondents without restriction to specific age groups or populations; (3) containing information on the study location (urban/suburban/rural); (4) presenting HBP prevalence without other associated comorbidities; (5) using a non-convenience sampling method and with a sample size above 500 participants. For studies published in more than one edition, we considered the most comprehensive one. When there was uncertainty or disagreement between the two authors as to the eligibility of a study, another author (Yuantao Hao) was asked for guidance to reach a consensus. The study selection process is shown in Fig. 1.

\section{Data extraction}

All data were extracted independently by two authors (Yun Huang, Pi Guo) using a standardized protocol. The characteristics recorded for each eligible study included the first author's name, year of publication, study design, sampling methods, age range of participants, net sample size (the total number of participants, and the number of male and female separately), number of events (hypertensive and pre-hypertensive cases), corresponding prevalence, methods of BP measurement (the type of device used, the number of $B P$ readings taken, and the time interval between the measurements), diagnostic criteria of hypertension, response rate, survey year, survey site, and location of study (urban/suburban/rural).

We then performed a quality assessment of the retained studies based on the completeness of the eligibility criteria, sampling strategy, age range, sample size, non-response rate, survey year, explanation of limitations of the study, and BP measurement techniques $[14,15]$. In total, twelve domains were assessed. A score of 1 was allocated for those fulfilling the conditions in each domain, a score of 0.5 for partial fulfilment, and a score of 0 for non-fulfillment of the conditions. The detailed scoring 


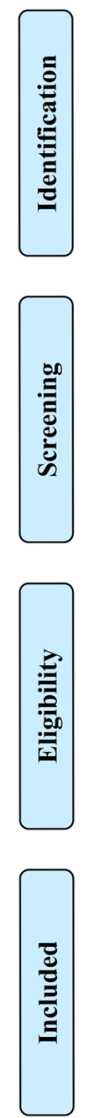

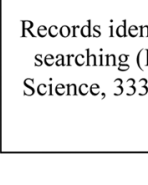

Records identified through database earching (PubMed, 228; Web of cience, 333; Embase, 386; $n=947$ )
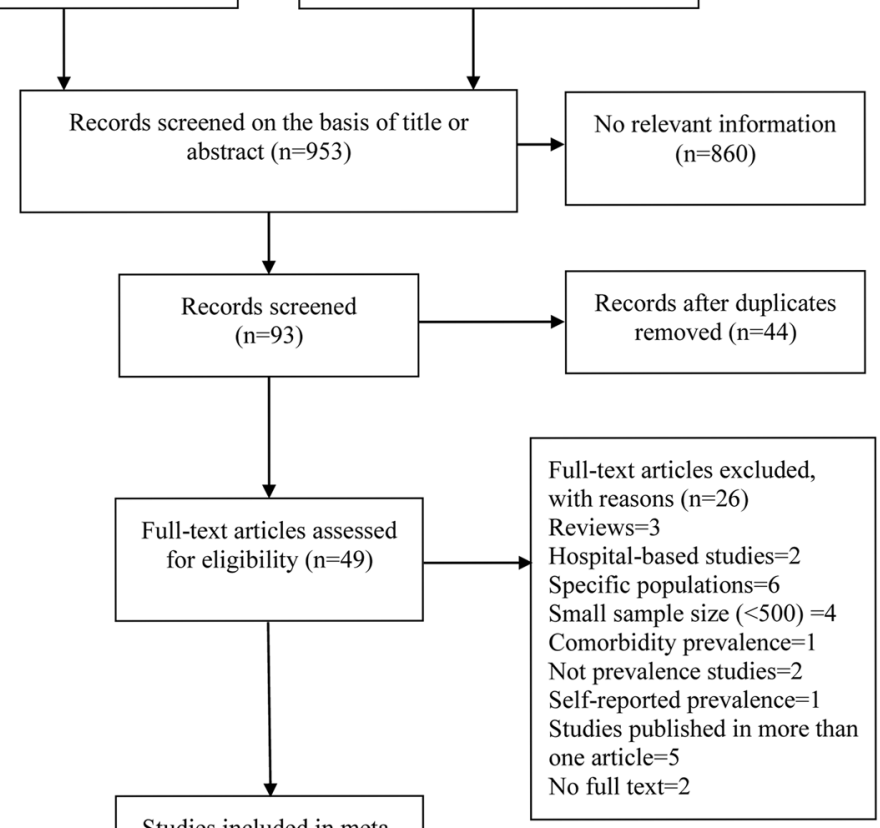

Studies included in metaanalysis $(n=23)$

Fig. 1 PRISMA flow diagram of the study selection process

table is provided as a Additional file 2. The maximum score was 12 and studies scoring 10.0 or above were considered high-qualified, those scoring 8.0-9.5 were classified as middle-qualified, and the rest were classed as low-qualified.

\section{Statistical analysis}

Meta-analysis was performed using the packages 'meta' and 'metafor' in R software (version 3.4.2). To weaken the effect of studies with extremely small or large prevalence on the overall estimate, we transformed the data with the Freeman-Tukey double arcsine function before pooling the prevalence [16]. We estimated heterogeneity among studies using Cochrane's chi-square $\left(\chi^{2}\right)$ test and quantified it with $I^{2}$ index. $I^{2}$ is defined as the proportion of total variation provided by between-study variation, and was denoted the values of $0,25,50$, and $75 \%$ which corresponds to no, low, moderate, and high heterogeneity, respectively [17]. A $p<0.05$ from Cochrane's chi-square $(\chi 2)$ test or large $I^{2}$ demonstrate substantial heterogeneity. Random-effects model was constructed to address heterogeneity in the pooled prevalence. An univariate meta-regression was performed by setting possible confounders as moderator with function 'rma.glmm' in the 'metafor' package to explore for sources of heterogeneity (a 5\% level of statistical significance), then we categorized studies into subgroups according to findings from the meta-regression and performed meta-analysis for each subgroup respectively to certify the results of the meta-regression. We applied the symmetry of funnel plots and did both Begg's adjusted-rank correlation test and Egger's regression asymmetry test to evaluate publication bias $[18,19]$; a $p$-value of less than 0.10 was considered indicative of statistically significant publication bias.

\section{Results \\ Study characteristics}

In total, 953 studies were retrieved, of which 23 met the inclusion criteria in the primary review of hypertension prevalence [6-11, 20-36]. It should be noted that one researcher (Sharma S.K.) had two publications that analyzed overlapping populations $[23,25]$. In the 2010 publication we only extracted pre-hypertensive data as this was not presented in the second report, and only hypertensive data were extracted from the 2011 publication. Three other studies conducted among specific gender groups were only included in the gender-specific subgroup analysis [21, 27, 30]. 
As can be observed from Table 1, the publication years spanned from 2006 to 2018 . The 23 retained studies totaled 99,792 participants (ranging from 527 to 15,934 participants). In the retained studies, the majority of participants were found to be above 18 years of age. The response rates of each survey varied from 69.2 to $99.6 \%$. Excepting two studies in which the surveyed time was not reported, eleven studies were conducted after 2010 and the other ten studies were conducted between 2001 to 2010. The surveyed sites covered Nepal broadly, among which six were from urban regions, six from suburban regions, six from rural areas, and five contained both urban and rural residents. In most of the studies analyzed, a manual sphygmomanometer $(n=12)$ was preferred, nine others used a digital sphygmomanometer, and two did not provide any information about the measuring device used. The frequency for taking BP measurements varied from one to four and the intervals between each measurement ranged from half a minute to half an hour. Each study was scored and ranked accordingly; out of these only three studies were identified as low-qualified [8, 30, 32].

\section{Burden of hypertension and prehypertension}

The HBP situation in Nepal is illustrated by the Forest plot in Fig. 2 Previous reports of HBP prevalence were found to vary widely, with rates ranging from 15.1 to $38.9 \%$. It is worth mentioning that seven out of nineteen studies showed prevalence higher than $30 \%$ and that the overall estimate was found to be $27.3 \%$ (95\% confidence interval (CI): $23.8-30.9 \%)$.

The pooled regional estimates of hypertension were 28.4\% (95\% CI: 22.4-34.7\%), 25.5\% (95\% CI: 21.4-29.8\%), and $24.4 \%$ (95\% CI: $17.9-31.6 \%$ ) for the urban, suburban, and rural areas respectively. HBP was found to be substantially affecting male (31.6\%; $95 \%$ CI: $27.3-36.1 \%)$ as compared to female (20.0\%; $95 \%$ CI: $14.2-26.6 \%)$, and this tendency was found to be consistent in three residential areas (Table 2).

Ten studies reported the prevalence of prehypertension $[7,8,10,11,22-24,31,32,36]$, among which, the lowest and highest rate was 22.1 and $48.0 \%$, and the pooled estimate was 35.4\% (Fig. 3; 95\% CI: 30.3-40.8\%). In addition, the prevalence of prehypertension was calculated to be highest in rural areas (40.4, 95\% CI: 25.4-56.4\%), followed by urban areas (29.3, 95\% CI: $20.8-38.5 \%)$, and lowest in the suburban areas (25.5, 95\% CI: $18.9-32.7 \%)$. And there was no significant difference between male $(39.0,95 \% \mathrm{CI}$ : 33.1-45.2\%) and female (37.0, 95\% CI: 27.1-47.6\%).

\section{Publication bias and sources of heterogeneity}

Figure 4 illustrates the Funnel plot for the visual assessment of publication bias and, as observed by the symmetrical pattern, no publication bias was found. In addition, both Begg's adjusted-rank correlation test and
Egger's regression asymmetry test showed no evidence of substantial publication bias $(P=0.861$ for Begg's test; $P=0.875$ for Egger's test).

Previous results showed a considerable heterogeneity $\left(I^{2}=99 \%\right.$ and $\left.P<0.01\right)$ among retained studies. Meta-regression findings indicated that sample size $(P=0.928)$, gender ratio $(P=0.948)$, inception of survey $(P=0.721)$, definition of hypertension $(P=0.363)$, quality score of study $(P=0.347)$, and measurement device $(P=0.769)$ were not associated with the heterogeneity observed (Table 3). Moreover, the age of participants $(P=0.001)$ and quality grade of each study we ranked $(P=0.027)$ were identified as potential sources of heterogeneity.

To certify the findings of meta-regression, subgroup analyses for specific age and quality grade groups were performed. The HBP prevalence was found to rise with an increase in age and was significantly higher among age group 40 or above $(36.8,95 \%$ CI: $29.4-44.5 \%)$ in contrast to that below 40 years (13.2, 95\% CI: 9.2-17.7\%; Table 2). Considering data limits, we just performed subgroup analyses for high- (22.6, 95\% CI: 16.4-29.5\%), middle- (38.6, 95\% CI: 36.9-40.3\%), and low- (21.4, 95\% CI: $19.1-23.7 \%)$ qualified studies within rural areas. It is noticeable that HBP prevalence among middle-qualified studies was actually higher than rates among high-qualified and low-qualified studies.

\section{Discussion}

The pooled prevalence of HBP obtained from our study was found to be $27.3 \%$ (95\% CI: $23.8-30.9 \%$ ), higher than that reported in low-income countries (23.1\%), but similar to the average rate in the SAARC regions $(27.1 \%)$ and that reported in the Nepal nationwide STEPS survey $(25.7 \%)$ [9, 37, 38]. A previous systematic review performed by Neupane D, et al. demonstrated partly comparable results with ours (29.7\%; 95\% CI: 26.9-32.6\%) [38]. However, there are some notable differences. First, Neupane $\mathrm{D}$, et al. aimed at the entire SAARC region's HBP prevalence and its associated risk factors rather than primarily focusing on the HBP prevalence of Nepalese as presented in our study. Second, they only included five original researches into their meta-analysis, which totaled nearly one-quarter of our participants $(n=22,939)$ and one of their included studies accounted for males only was not representative of Nepalese in general. Thus, a more comprehensive analysis was necessary to reveal the present Nepalese HBP situation.

Previous literature on HBP prevalence often categorized residents by urban and rural regions, while we subdivided residents into three categories, namely urban, suburban, and rural, for an improved practical and factual analysis. Based on the regional analysis, although the HBP status appeared somewhat more severe in urban regions, we found that the prevalence of the three 


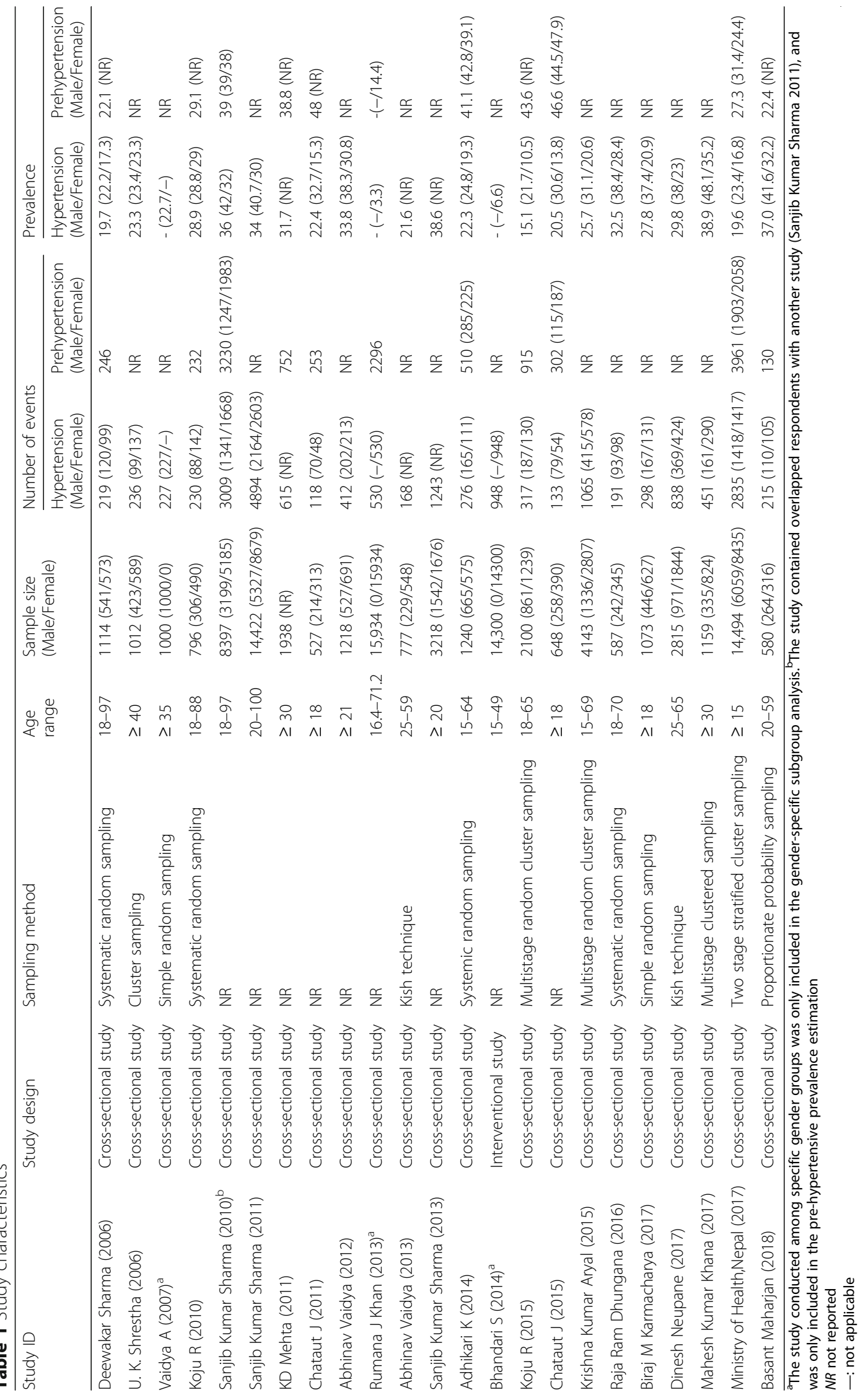




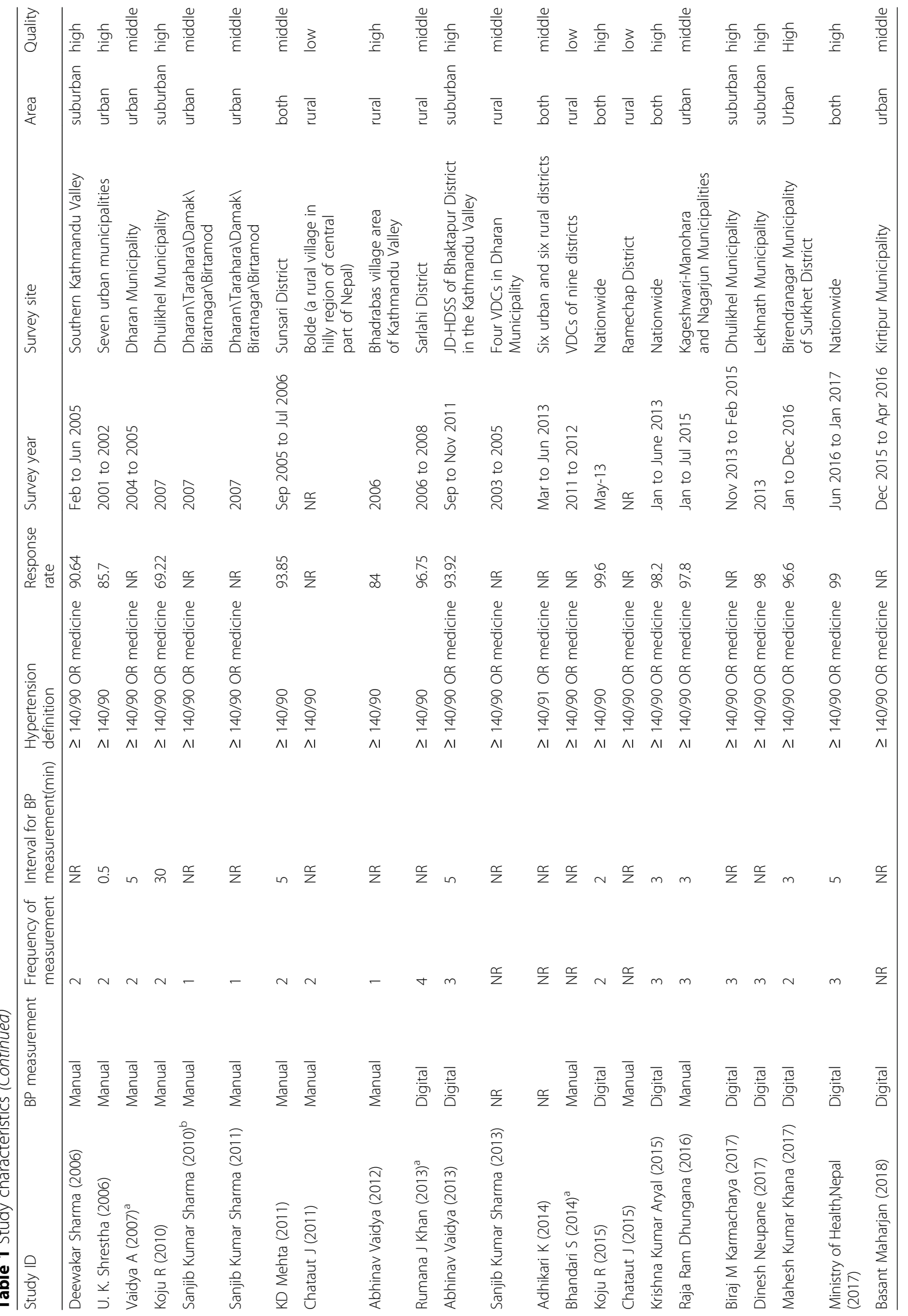




\begin{tabular}{|c|c|c|c|c|c|c|c|}
\hline Study & Events & Total & & & Proportion & $95 \%-\mathrm{Cl}$ & Weight \\
\hline Deewakar Sharma (2006) & 219 & 1114 & + & & 0.197 & {$[0.174 ; 0.221]$} & $5.3 \%$ \\
\hline U. K. Shrestha (2006) & 236 & 1012 & $\longrightarrow$ & & 0.233 & {$[0.207 ; 0.261]$} & $5.2 \%$ \\
\hline Koju R (2010) & 230 & 796 & & 1 & 0.289 & {$[0.258 ; 0.322]$} & $5.2 \%$ \\
\hline Sanjib Kumar Sharma (2011) & 4894 & 14422 & & + & 0.339 & {$[0.332 ; 0.347]$} & $5.4 \%$ \\
\hline KD Mehta (2011) & 615 & 1938 & & + & 0.317 & {$[0.297 ; 0.339]$} & $5.3 \%$ \\
\hline Chataut J (2011) & 118 & 527 & 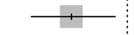 & & 0.224 & {$[0.189 ; 0.262]$} & $5.1 \%$ \\
\hline Abhinav Vaidya (2012) & 412 & 1218 & & $\longrightarrow$ & 0.338 & {$[0.312 ; 0.366]$} & $5.3 \%$ \\
\hline Abhinav Vaidya (2013) & 168 & 777 & $\div$ & & 0.216 & {$[0.188 ; 0.247]$} & $5.2 \%$ \\
\hline Sanjib Kumar Sharma (2013) & 1243 & 3218 & & + & 0.386 & {$[0.369 ; 0.403]$} & $5.4 \%$ \\
\hline Adhikari K (2014) & 276 & 1240 & + & & 0.223 & {$[0.200 ; 0.247]$} & $5.3 \%$ \\
\hline Koju R (2015) & 317 & $2100+$ & & & 0.151 & {$[0.136 ; 0.167]$} & $5.3 \%$ \\
\hline Chataut J (2015) & 133 & 648 & $\div$ & & 0.205 & {$[0.175 ; 0.238]$} & $5.2 \%$ \\
\hline Krishna Kumar Aryal (2015) & 1065 & 4143 & + & & 0.257 & {$[0.244 ; 0.271]$} & $5.4 \%$ \\
\hline Raja Ram Dhungana (2016) & 191 & 587 & & 1 & 0.325 & {$[0.288 ; 0.365]$} & $5.1 \%$ \\
\hline Biraj M Karmacharya (2017) & 298 & 1073 & & $\div$ & 0.278 & {$[0.251 ; 0.306]$} & $5.3 \%$ \\
\hline Dinesh Neupane (2017) & 838 & 2815 & & + & 0.298 & {$[0.281 ; 0.315]$} & $5.3 \%$ \\
\hline Mahesh Kumar Khanal (2017) & 451 & 1159 & & $\longrightarrow$ & 0.389 & {$[0.361 ; 0.418]$} & $5.3 \%$ \\
\hline Ministry of Health,Nepal (2017) & 2835 & 14494 & + & & 0.196 & {$[0.189 ; 0.202]$} & $5.4 \%$ \\
\hline Basant Maharjan (2018) & 215 & 580 & & $\div$ & 0.371 & {$[0.331 ; 0.411]$} & $5.1 \%$ \\
\hline $\begin{array}{l}\text { Random effects model } \\
\text { Heterogeneity: } I^{2}=99 \%, p<0.01\end{array}$ & & 53861 & & & 0.273 & {$[0.238 ; 0.309]$} & $100.0 \%$ \\
\hline
\end{tabular}

Fig. 2 Prevalence of hypertension in Nepal

areas was comparable, and this was in accordance with an insignificant difference between urban and rural habitation presented in previous studies $[9,10]$. The primary driver for this observed phenomenon may be rapid urbanization, change in dietary patterns, and behavioral factors like smoking and harmful drinking that result in suburban and rural residents catching up with urban populations in the process of exacerbating NCDs [39].

Higher HBP prevalence in male compared to female was found in our study, which was similar to that of two previous systematic reviews $[37,38]$. It is worth mentioning that there were only two studies [20,22], out of the seventeen which mentioned prevalence in both male and female, that reported no considerable differences

Table 2 Prevalence of hypertension in Nepal classified by area, age, and gender

\begin{tabular}{llll}
\hline Characteristics & Male & Female & Both genders \\
\hline $\begin{array}{llll}\text { Residence } \\
\text { Urban }\end{array}$ & $33.8(26.3,41.8)$ & $27.6(20.9,34.8)$ & $28.4(22.4,34.7)$ \\
Suburban & $31.5(23.8,39.7)$ & $22.4(18.5,26.5)$ & $25.5(21.4,29.8)$ \\
Rural & $30.2(20.5,40.9)$ & $13.1(7.7,19.6)$ & $24.4(17.9,31.6)$ \\
Age (years) & & & \\
$<30$ & $7.0(6.0,8.2)$ & $2.8(2.1,3.4)$ & $8.1(4.9,12.0)$ \\
$30-39$ & $24.4(15.3,34.8)$ & $13.4(9.5,17.9)$ & $16.2(13.8,18.7)$ \\
$40-49$ & $32.6(19.3,47.4)$ & $29.1(19.5,39.8)$ & $28.9(22.4,35.8)$ \\
$50-59$ & $44.9(27.7,62.7)$ & $39.4(26.6,53.0)$ & $35.6(26.8,45.0)$ \\
$\geq 60$ & $44.7(33.7,55.9)$ & $44.7(33.3,56.5)$ & $43.5(33.8,53.5)$ \\
$<40$ & $19.9(9.0,33.7)$ & $10.7(4.6,19.0)$ & $13.2(9.2,17.7)$ \\
$\geq 40$ & $41.8(29.6,54.4)$ & $37.9(28.0,48.4)$ & $36.8(29.4,44.5)$ \\
Total & $31.6(27.3,36.1)$ & $20.0(14.2,26.6)$ & $27.3(23.8,30.9)$ \\
\hline
\end{tabular}

between the genders. In addition, our findings also revealed that higher HBP in male was consistent in urban, suburban, and rural areas. This gender difference may be attributed to male as they are more easily exposed to behavioral risk factors, such as a significantly high level of tobacco and alcohol use [31].

The pooled prehypertension prevalence in our findings was similar to the estimated global figure $(35.4 \%$ vs. $38.0 \%$ respectively) while higher than that of the SAARC region $(29.6 \%)$ [38, 40]. Furthermore, results of this meta-analysis identified that the prevalence of prehypertension is more alarming in Nepalese rural populations (40.4\%), with the status in urban residents (29.3\%) concerning as well, while suburban residents comparably retain a more "comfortable" status (25.5\%). We did not find significant differences between male and female as previous reviews did [38, 40]. It is undeniable that prehypertension would probably lead to a considerable burden of hypertension in the coming future. Thus, an urgent need for prioritizing its status is strongly recommended. The findings of this study provide crucial information for Nepalese local authorities to distinguish where to focus awareness and screening programs.

The reported HBP prevalence varied considerably across the included studies indicated a notable heterogeneity. The results of meta-regression and subgroup analyses suggested that heterogeneity was directly associated with the age of participants and the quality grade of the included studies. Further, we found that the prevalence was significantly higher in the middle-aged ( $\geq 40$ years) compared to that in younger adults ( $<40$ years). Based on the wide and multi-database literature-search, we are the first to provide strong evidence for such an age boundary. A reasonable explanation was given by a previous study which 


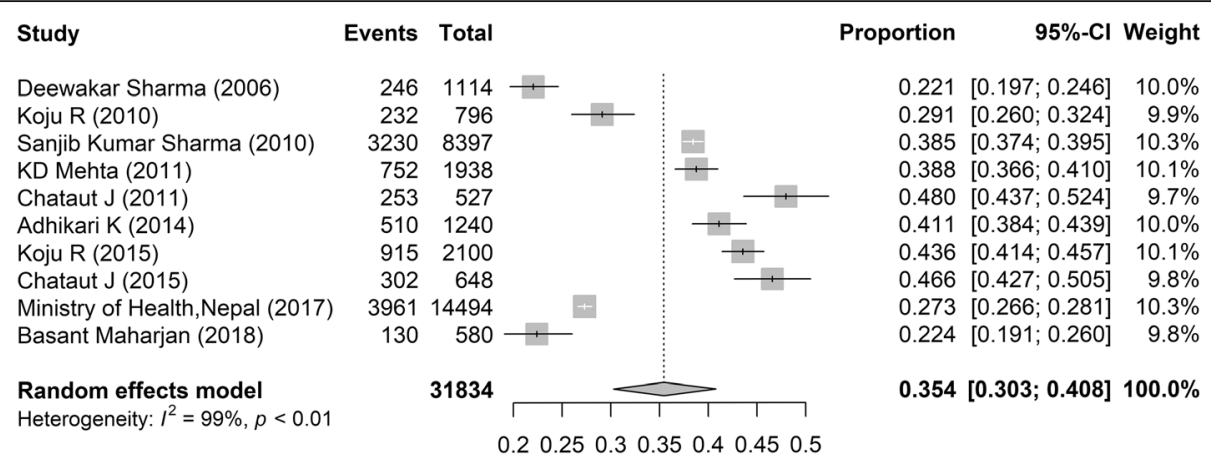

Fig. 3 Prevalence of prehypertension in Nepal

suggested that age-related structural changes in blood vessels gradually lead to narrowing of the vascular lumen, and consequently could increase the risk of acquiring HBP [41]. For studies conducted in rural areas, middlequality studies showed a significantly higher prevalence. As to the heterogeneity resulting from respondents' age, we recalculated the HBP prevalence, with the exclusion of three studies, that included a non-generalized age range without younger adults [6,20,24], and the estimate was found to decrease slightly from 27.3 to $26.5 \%$ (95\% CI: $22.7-30.6 \%$ ), this may be a more precise figure reflective of present Nepalese hypertension status.

It is worth mentioning that Nepal has developed the national Multi-sectoral Action Plan for prevention and control of NCDs (2014-2020), including hypertension prevention and management for the prevention of cardiovascular disease [42]. One of the programs under the action plan is the WHO Package of Essential Non-communicable disease interventions for primary health care in low-resource settings, which began implementation in Nepal in

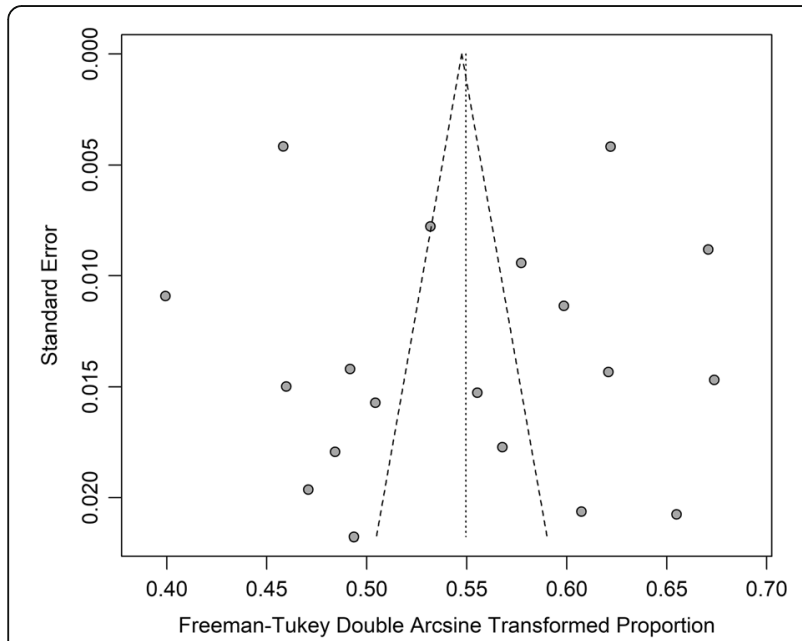

Fig. 4 Funnel plot showing the transformed proportion of hypertension in each study by the standard error
2016. The program will cover 75 districts in a 5-year period in Nepal and will continue providing access to the diagnostic services in primary health care settings [43]. These plans may bring feasible ways of mitigating the burden of NCDs.

To our knowledge, this is the first comprehensive report targeted at evaluating the scientific literature on the prevalence of hypertension and prehypertension in the urban, suburban, and rural populations of Nepal. Despite such findings, there are some limitations of this study that should be mentioned. Studies from only three of the most commonly used platforms (PubMed, EMBASE, and Web of Science) were searched. Several included articles provided only a crude prevalence with no specified hypertensive events. Further, a noteworthy heterogeneity was observed among retained studies so that large-scale nationwide and more representative epidemiological studies are needed to confirm the results of this study.

Table 3 Results of the meta-regression model

\begin{tabular}{llll}
\hline Moderators & Coefficient & Standard error & $P$-value \\
\hline Mean age & 0.069 & 0.022 & $0.001^{*}$ \\
Sample size & 0.000 & 0.000 & 0.928 \\
Gender (male ratio) & -0.078 & 1.191 & 0.948 \\
Inception of survey & -0.007 & 0.018 & 0.721 \\
Definition of hypertension & & & 0.363 \\
$\quad \geq 140 / 90$ OR medicine & Reference & & \\
$\geq 140 / 90$ & -0.167 & 0.183 & 0.363 \\
Quality score of study & -0.057 & 0.061 & 0.347 \\
Quality grade & & & $0.027^{*}$ \\
$\quad$ middle & Reference & & \\
$\quad$ high & -0.351 & 0.155 & $0.023^{*}$ \\
$\quad$ low & -0.568 & 0.255 & $0.026^{*}$ \\
Measurement device & & & 0.769 \\
$\quad$ manual & Reference & & 0.769 \\
$\quad$ digital & -0.0497 & 0.1696 &
\end{tabular}




\section{Conclusion}

This systematic review identified an alarming situation of hypertension in Nepalese male and middle-aged ( $\geq 40$ years), as well as a situation of concern regarding the prehypertension status which affects almost $40 \%$ of the rural population. Improving the population-level awareness of HBP; facilitating routine screening aiming at those high-risk groups through integrating of NCDs with primary health care; and effective implementation of NCDs Multisectoral Action Plan (2014-2020) offer potential means for addressing the burden of increased blood pressure in Nepal.

\section{Additional files}

Additional file 1: Prisma Checklist. (DOC 64 kb)

Additional file 2: Scoring table for quality assessment of the retained studies. (DOCX $14 \mathrm{~kb}$ )

\section{Abbreviations}

BP: Blood pressure; Cl: Confidence interval; HBP: High blood pressure: LMICs: Low- and middle-income countries; MeSH: Medical Subject Headings; NCDs: Non-communicable diseases; PRISMA: Preferred Reporting Items for Systematic Reviews and Meta-Analyses; SAARC: South Asian Association for Regional Cooperation; WHO: World Health Organization

\section{Acknowledgements}

Not applicable.

Funding

None.

\section{Availability of data and materials}

All data generated or analysed during this study are included in this published article and its Additional files.

\section{Authors' contributions}

YTH designed the study. YH and PG extracted relevant articles for the review. $\mathrm{YH}$ analyzed the data. $\mathrm{YH}, \mathrm{PG}, \mathrm{BM}, \mathrm{SR}, \mathrm{DX}$, and $\mathrm{YTH}$ contributed in drafting the manuscript, literature review, and interpretation of findings. All authors read and approved the final manuscript.

\section{Ethics approval and consent to participate}

Not applicable.

\section{Consent for publication}

Not applicable.

\section{Competing interests}

The authors declare that they have no competing interests.

\section{Author details}

${ }^{1}$ Department of Medical Statistics and Epidemiology, School of Public Health, Sun Yat-sen University, No. 74 Zhongshan Road II, Guangzhou 510080, Guangdong Province, People's Republic of China. ${ }^{2}$ Department of Preventive Medicine, Shantou University Medical College, Shantou 515041, Guangdong Province, China. ${ }^{3}$ Sun Yat-sen Global Health Institute (SGHI), School of Public Health and Institute of National Governance of Sun Yat-sen University, Guangzhou 510275, Guangdong Province, China. ${ }^{4}$ Department of Gastric Surgery, Sun Yat-sen University Cancer Center, State Key Laboratory of Oncology in South China, Collaborative Innovation Center for Cancer Medicine, Guangzhou 510060, Guangdong Province, China.
Received: 9 January 2019 Accepted: 8 April 2019

Published online: 30 April 2019

\section{References}

1. Perkovic V, Huxley R, Wu Y, Prabhakaran D, MacMahon S. The burden of blood pressure-related disease: a neglected priority for global health. Hypertension. 2007;50:991-7.

2. Poulter NR, Prabhakaran D, Caulfield M. Hypertension. Lancet. 2015;386:801-12

3. World Health Organization. A global brief on hypertension: silent killer, global public health crisis: World Health Day; 2013. https://www.who.int/ cardiovascular_diseases/publications/global brief hypertension/en/.

4. Mishra SR, Neupane D, Bhandari PM, Khanal V, Kallestrup P. Burgeoning burden of non-communicable diseases in Nepal: a scoping review. Glob Health. 2015;11:1-10.

5. Ibrahim MM, Damasceno A. Hypertension in developing countries. Lancet 2012;380:611-9.

6. Khanal MK, Dhungana RR, Bhandari P, Gurung Y, Paudel KN. Prevalence, associated factors, awareness, treatment, and control of hypertension: findings from a cross sectional study conducted as a part of a community based intervention trial in Surkhet, mid-western region of Nepal. PLoS One. 2017. https://doi.org/10.1371/journal.pone.0185806.

7. Sharma D, Bkc M, Rajbhandari S, Raut R, Baidya SG, Kafle PM, et al. Study of prevalence, awareness, and control of hypertension in a suburban area of Kathmandu, Nepal. Indian Heart J. 2006:58:34-7.

8. Chataut J, Adhikari RK, Sinha NP. Prevalence and risk factors for hypertension in adults living in central development region of Nepal. Kathmandu Univ Med J. 2011;9:13-8.

9. Aryal KK, Mehata S, Neupane S, Vaidya A, Dhimal M, Dhakal P, et al. The burden and determinants of non-communicable diseases risk factors in Nepal: findings from a nationwide STEPS survey. PLoS One. 2015. https:// doi.org/10.1371/journal.pone.0134834

10. Koju R, Manandhar K, Risal A, Steiner TJ, Holen A, Linde M. Undertreated hypertension and its implications for public health in Nepal: Nationwide population-based survey. Kathmandu Univ Med J. 2015;13:3-7.

11. Ministry of Health, Nepal; New ERA; and ICF. Nepal Demographic and Health Survey 2016: Key Indicators. Kathmandu: Ministry of Health, Nepal; 2017.

12. Moher D, Liberati A, Tetzlaff J, Altman DG, The PRISMA group. Preferred reporting items for systematic reviews and Meta-analyses: the PRISMA statement. PLoS Med. 2009. https://doi.org/10.1371/journal.pmed1000097.

13. Chobanian AV, Bakris GL, Black HR, Cushman WC, Green LA, Izzo JL, et al. The seventh report of the joint National Committee on prevention, detection, evaluation, and treatment of high blood pressure: the JNC 7 report. JAMA. 2003;289:2560-72.

14. BOYLE MH. Guidelines for evaluating prevalence studies. Evid Based Ment Health. 1998;1:37-9.

15. Vandenbroucke JP, von Elm E, Altman DG, Gotzsche PC, Mulrow CD, Pocock SJ, et al. Strengthening the reporting of observational studies in epidemiology (STROBE): explanation and elaboration. Int J Surg. 2014:12:1500-24.

16. Barendregt JJ, Doi SA, Yong YL, Norman RE, VoS T. Meta-analysis of prevalence. J Epidemiol Community Health. 2013:67:974-8.

17. Higgins JP, Thompson SG, Deeks JJ, Altman DG. Measuring inconsistency in meta-analyses. BMJ. 2003:327:557-60.

18. Begg CB, Mazumdar M. Operating characteristics of a rank correlation test for publication bias. Biometrics. 1994;50:1088-101.

19. Egger M, Davey SG, Schneider M, Minder C. Bias in meta-analysis detected by a simple, graphical test. BMJ. 1997;315:629-34.

20. Shrestha UK, Singh DL, Bhattarai MD. The prevalence of hypertension and diabetes defined by fasting and 2-h plasma glucose criteria in urban Nepal. Diabet Med. 2006:23:1130-5.

21. Vaidya A, Pokharel PK, Karki P, Nagesh S. Exploring the iceberg of hypertension: a community based study in an eastern Nepal town. Kathmandu Univ Med J. 2007;5:349-59.

22. Koju R, Manandhar K, Gurung R, Pant P, Bedi T. Prevalence of hypertension in semi-urban area of Nepal. Nepalese Heart Journal. 2010;7:1277-84.

23. Sharma SK, Zou H, Togtokh A, Ene-lordache B, Carminati S, Remuzzi A, et al. Burden of CKD, proteinuria, and cardiovascular risk among Chinese, Mongolian, and Nepalese participants in the international society of nephrology screening programs. Am J Kidney Dis. 2010;56:915-27.

24. Mehta KD, Karki P, Lamsal M, Paudel IS, Majhi S, Das BK, et al. Hyperglycemia, glucose intolerance, hypertension and socioeconomic position in eastern Nepal. Southeast Asian J Trop Med Public Health. 2011;42:197-207. 
25. Sharma SK, Ghimire A, Radhakrishnan J, Thapa L, Shrestha NR, Paudel N, et al. Prevalence of hypertension, obesity, diabetes, and metabolic syndrome in Nepal. Int J Hypertens. 2011;2011:821971.

26. Vaidya A, Pathak RP, Pandey MR. Prevalence of hypertension in Nepalese community triples in 25 years: a repeat cross-sectional study in rural Kathmandu. Indian Heart J. 2012;64:128-31.

27. Khan RJ, Stewart CP, Christian P, Schulze KJ, Wu L, Leclerq SC, et al. A crosssectional study of the prevalence and risk factors for hypertension in rural Nepali women. BMC Public Health. 2013;13:55.

28. Vaidya A, Aryal UR, Krettek A. Cardiovascular health knowledge, attitude and practice/behaviour in an urbanising community of Nepal: a population-based cross-sectional study from Jhaukhel-Duwakot health demographic surveillance site. BMJ Open. 2013. https://doi.org/10.1136/bmjopen-2013-002976.

29. Sharma SK, Dhakal S, Thapa L, Ghimire A, Tamrakar R, Chaudhary S, et al. Community-based screening for chronic kidney disease, hypertension and diabetes in Dharan. J Nepal Med Assoc. 2013;52:205-12.

30. Bhandari S, Sayami JT, Sayami M, Kandel BP, Banjara MR. General health status of women of reproductive age in Nepal. J Nepal Health Res Counc. 2014;12:8-13.

31. Adhikari K, Gupta N, Koshy AK. Gender differences on risk factors of noncommunicable diseases--a community based cross-sectional study in Central Nepal. J Nepal Health Res Counc. 2014;12:89-93.

32. Chataut J, Khanal K, Manandhar K. Prevalence and associated factors of hypertension among adults in rural Nepal: a community based study. Kathmandu Univ Med J. 2015;13:346-50

33. Dhungana RR, Pandey AR, Bista B, Joshi S, Devkota S. Prevalence and associated factors of hypertension: a community-based cross-sectional study in municipalities of Kathmandu, Nepal. Int J Hypertens. 2016;2016:1-10.

34. Karmacharya BM, Koju RP, LoGerfo JP, Chan KCG, Mokdad AH, Shrestha A, et al. Awareness, treatment and control of hypertension in Nepal: findings from the Dhulikhel heart study. Heart Asia. 2017;9:1-8.

35. Neupane D, Shrestha A, Mishra SR, Bloch J, Christensen B, McLachlan CS, et al. Awareness, prevalence, treatment, and control of hypertension in Western Nepal. Am J Hypertens. 2017;30:907-13.

36. Maharjan B. Prevalence and awareness of hypertension among adults and its related risk factors. J Nepal Health Res Counc. 2018;15:242-6.

37. Sarki AM, Nduka CU, Stranges S, Kandala NB, Uthman OA. Prevalence of hypertension in low- and middle-income countries: a systematic review and Meta-analysis. Medicine (Baltimore). 2015;94:e1959.

38. Neupane D, McLachlan CS, Sharma R, Gyawali B, Khanal V, Mishra SR, et al. Prevalence of hypertension in member countries of south Asian Association for Regional Cooperation (SAARC): systematic review and meta-analysis. Medicine (Baltimore). 2014;93:e74

39. World Bank. Non-communicable disease in Nepal-Nepal's next major health challenge in: NCDs policy brief-Nepal. Washington DC: World Bank; 2011.

40. Guo X, Zheng L, Zhang X, Zou L, Li J, Sun Z, et al. The prevalence and heterogeneity of prehypertension: a meta-analysis and meta-regression of published literature worldwide. Cardiovasc J Afr. 2012;23:44-50.

41. Pinto E. Blood pressure and ageing. Postgrad Med J. 2007;83:109-14.

42. Government of Nepal; World Health Organization Country Office for Nepal. Multisectoral Action Plan for the Prevention and Control of NonCommunicable Diseases (2014-2020); 2014. p. 15-6.

43. Upreti SR, Lohani GR, Magtymova A, Dixit LP. Strengthening policy and governance to address the growing burden of diabetes in Nepal. WHO Southeast Asia J Public Health. 2016:5:40-3.

Ready to submit your research? Choose BMC and benefit from:

- fast, convenient online submission

- thorough peer review by experienced researchers in your field

- rapid publication on acceptance

- support for research data, including large and complex data types

- gold Open Access which fosters wider collaboration and increased citations

- maximum visibility for your research: over $100 \mathrm{M}$ website views per year

At BMC, research is always in progress.

Learn more biomedcentral.com/submissions 